\title{
Identification of Lactic Acid Bacteria Isolated From Fruits and Industrial Byproducts of Fruits Through the MALDI-TOF Technique
}

Estefânia Fernandes Garcia (I), Danilo Elias Xavier (I), Whyara Karolina Almeida Costa (I), Rayssa Julliane de Carvalho (I), Eloísa Helena Campana (II), Renata Cristina Picão (II), Marciane Magnani (I), Maria Saarela (III), Evandro Leite de Souza (I)

(I) UFPB - Federal University of Paraíba (Cidade Universitária - João Pessoa - PB - Brasil CEP: 58051-900), (II) UFRJ - Federal University of Rio de Janeiro (Av. Pedro Calmon, $n^{\circ} 550$ - Rio de Janeiro, RJ - CEP 21941-901 ), (III) VTT TRCF - VTT Technical Research Centre of Finland ( P.O. Box 1000, FI-02044 VTT, Finland)

\section{Resumo}

LAB strains with probiotic potential have been isolated from human and animal gastrointestinal tract, but it seems that plant matrices can be potential sources of these bacteria. An important aspect in research studies on LAB with probiotic potential is the use of a fast and effective preliminary method to identify genera of interest. The use of mass spectrometry (MS) by MALDI-TOF has shown efficiency and correspondence with reliable methods for bacterial identification. This work aimed to isolate lactic acid bacteria strains from fruits (mango and acerola) and byproducts generated in the industrial processing of fruit pulp and identify them through MS. After homogenization and dilution of each sample, an aliquot was inoculated on agar plates containing MRS and M17 agar, incubated at 37 and $30^{\circ} \mathrm{C}$, respectively, under anaerobic conditions (48-72h). Colonies were evaluated for their morphological characteristics. Ten colonies of each morphological type were selected for initial identification (Gram positive and catalase-negative), and then submitted to MS identification using the MALDI Biotyper (Bruker) platform, which uses the Matrix Assisted Laser Desorption Ionization - Time of Flight technique (MALDI-TOF). Among the isolates obtained from acerola,

\footnotetext{
Referência:

Estefânia Fernandes Garcia, Danilo Elias Xavier, Whyara Karolina Almeida Costa, Rayssa Julliane de Carvalho, Eloísa Helena Campana, Renata Cristina Picão, Marciane Magnani, Maria Saarela, Evandro Leite de Souza. Identification of Lactic Acid Bacteria Isolated From Fruits and Industrial Byproducts of Fruits Through the Maldi-Tof Technique. In: Anais do $12^{\circ}$ Congresso Latinoamericano de Microbiologia e Higiene de Alimentos - MICROAL 2014 [= Blucher Food Science Proceedings, num.1, vol.1]. São Paulo: Editora Blucher, 2014. DOI $10.5151 /$ foodsci-microal-260
} 
Lactococcus lactis e Lactobacillus plantarum identified; among isolates obtained from acerola byproducts, L. fermentum, L. plantarum, L. brevis and L. nagelii identified. Among the isolates obtained from mango, Leuconostoc mesenteroides, Pedicococcus pentosaceus and L. nagelii identified, while in mango byproducts, L. plantarum, L. fermentum, L. nagelii, L. pentosus and Leuconostoc mesenteroides found. About $60 \%$ of strains identified have satisfactory score to confirm genus and probable species, while $32 \%$ of strains showed equivalent score and probable genus, in agreement with other morphological features previously observed. The use of MALDI-TOF to identify LAB proved to be an effective method for the selection of strains of interest, but still requires confirmation of identification by molecular biology techniques.

Palavras-Chave: probiotic, mass spectrometry, Lactobacillus Agência de Fomento: $\mathrm{CNPq}$ 